\title{
The association between household food insecurity and obesity in Mexico: a cross-sectional study of ENSANUT MC 2016
}

\author{
Rosa Elena Ponce-Alcala ${ }^{1, *}$, Jose Luis Ramirez-Garcia Luna ${ }^{2}$, Teresa Shamah-Levy ${ }^{3}$ and \\ Hugo Melgar-Quiñonez ${ }^{1}$ \\ 'Margaret A Gilliam Institute for Global Food Security, School of Human Nutrition, McGill University, Macdonald \\ Campus, 2111 Lakeshore Road, Sainte-Anne-de-Bellevue, QC H9X 3V9, Canada: 2Division of Experimental Surgery, \\ Department of Surgery, Faculty of Medicine, McGill University, Montreal General Hospital, Montreal, QC, Canada: \\ ${ }^{3}$ Surveys and Evaluation Research Center, National Institute of Public Health (INSP), Santa María Ahuacatitlán, \\ Cerrada Los Pinos y Caminera, Cuernavaca, Morelos, Mexico
}

Submitted 4 September 2020: Final revision received 12 June 2021: Accepted 29 July 2021: First published online 25 August 2021

\begin{abstract}
Objective: To examine the association between household food insecurity and overweight, obesity and abdominal obesity in Mexican adults.

Design: Cross-sectional study.

Setting: We analysed data from the Mexican Halfway National Health and Nutrition Survey 2016, a nationally representative survey that accounted for rural and urban areas in four regions of Mexico: North, Centre, Mexico City and South.

Participants: Adults from 20 to 59 years old ( $n$ 5456, which represents 45804210 individuals at the national level).

Results: $70 \cdot 8 \%$ of the Mexican adults had some degree of household food insecurity. This situation showed larger proportions $(P<0.05)$ among indigenous people, those living in a rural area, in the Southern region or the lowest socio-economic quintiles. The prevalence of obesity and abdominal obesity was higher in female adults $(P<0 \cdot 001)$, with the highest proportions occurring among those experiencing severe household food insecurity. Among women, mean BMI and waist circumference were higher as household food insecurity levels increased $(P<0.001)$. According to multivariate logistic regression models, severe household food insecurity showed to be positively associated with obesity (OR: 2.36; $P=0 \cdot 001)$ in Mexican adult females.

Conclusions: Our findings confirm the association between household food insecurity and obesity among Mexican women. Given the socio-demographic characteristics of the food-insecure population, it is alarming that prevailing socio-economic inequalities in the country might also be contributing to the likelihood of obesity. Therefore, it is crucial to maintain and bolster surveillance systems to track both problems and implement adequate policies and interventions.
\end{abstract}

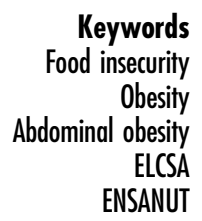

Food insecurity exists when people lack secure access to sufficient amounts of safe and nutritious food for normal growth and development and an active and healthy life ${ }^{(1)}$. This condition derives in deficient nutritional status and affects social and mental well-being, physical health and overall quality of life ${ }^{(2)}$. Food insecurity has been classified in three categories: (i) mild food insecurity, defined as worrying about not being able to obtain enough food and/or decreasing dietary quality, (ii) moderate food insecurity, which refers to compromising not only the quality but the quantity of the food consumed as well and (iii) lastly, severe food insecurity that exists when people experience hunger episodes ${ }^{(3)}$.

The presence of obesity in situations of economic and food scarcity was identified since 1965 when Goldblatt et al. observed a markedly larger obesity prevalence among people from low socio-economic status in Manhattan ${ }^{(4)}$. Thirty years later, Dietz described a similar situation in a case report and proposed that either food choices (i.e. cheap and high-calorie foods) or physiological adaptations

*Corresponding author: Email rosa.poncealcala@mail.mcgill.ca

(c) The Author(s), 2021. Published by Cambridge University Press on behalf of The Nutrition Society 
responding to food scarcity episodes could be responsible for this paradoxical association ${ }^{(5)}$. Since then, the evidence supporting those arguments has increased, especially in the $\mathrm{USA}^{(6-9)}$ and Latin America ${ }^{(10-14)}$. For instance, a study that evaluated Mexican households reported an inverse relationship between food insecurity and income ${ }^{(15)}$. Additionally, in comparison with food-secure households, food-insecure families showed significantly lower expenditure on fruits, vegetables, meats and dairy, while their spending on eggs, legumes, sugar, fats and oils was higher ${ }^{(15)}$. Other studies have also reported that poverty is a common factor in food insecurity and obesity ${ }^{(16)}$. This condition leads to higher consumption of nutrient-poor, energy-dense foods, which are more affordable ${ }^{(16)}$. Furthermore, stress and other psychological and social consequences of poverty can have a negative impact on body weight, hormonal balance and metabolic functions ${ }^{(17)}$.

In Mexico, the last decades have been characterised by an economical and nutritional transition, where the intake of ultra-processed and densely caloric foods has increased, accompanied by more sedentary lifestyles, contributing to a rapid increment in the rates of obesity and chronic illnesses ${ }^{(10)}$. Since 1980, adult obesity prevalence has tripled $^{(18)}$, and today, the country ranks second highest at the global level ${ }^{(19)}$. Moreover, complications such as type II diabetes and cardiovascular problems are the leading causes of death among Mexican people ${ }^{(20)}$. Therefore, obesity is one of the most relevant public health issues $^{(18)}$. According to the Mexican Halfway National Health and Nutrition Survey 2016 (ENSANUT MC 2016 by its acronym in Spanish, Encuesta Nacional de Salud y Nutrición Medio Camino 2010), a nationwide survey conducted by the National Institute of Public Health of Mexico (INSP by its acronym in Spanish, Instituto Nacional de Salud Pública), adult overweight and obesity mixed prevalence was $72.5 \%$, and the prevalence of abdominal obesity was $76 \cdot 6 \%{ }^{(21)}$.

Simultaneously, food insecurity has also been a problem for the country during the last years. In 2008, this phenomenon was measured for the first time nationwide by the National Council for the Evaluation of Social Development Policy (CONEVAL for its acronym in Spanish, Consejo Nacional de Evaluación de la Politica de Desarrollo Social). At that time, it was estimated that $21.7 \%$ of the population lacked access to food, a condition that encompasses both moderate and severe food insecurity ${ }^{(22)}$. This prevalence decreased to $20.4 \%$ in $2018^{(22)}$. Nonetheless, the number of affected people increased from 24.3 to 25.5 million during that period $^{(22)}$. Moreover, considering mild food insecurity, a total of 49.7 million people experienced some degree of food insecurity in $2018^{(22)}$. For its part, the ENSANUT has reported even higher figures in 2012 and 2016. Without significant changes from one period to another, food insecurity was reported at $69.5 \%$ in $2016^{(23)}$.
According to 2012 national data, mild food insecurity is associated with obesity ${ }^{(11)}$ and diabetes in women, and with hypertension in men and women ${ }^{(24)}$. Correspondingly, it has been suggested that food insecurity might be leading people to consume high amounts of sugar, fat and refined carbohydrates ${ }^{(11,24)}$. Furthermore, the stress related to living in a scarcity situation could contribute to increased visceral fat deposition $^{(24)}$. Thereby, attending food insecurity is crucial to solving the ongoing nutritional epidemic ${ }^{(11,24)}$. Accordingly, researchers have urged the government to improve the performance of assistance programmes while addressing the roots of food insecurity ${ }^{(11,24)}$.

Since 2013, the Mexican government has increased efforts to confront poverty and hunger ${ }^{(25)}$. For instance, the National Strategy for Inclusion (Estrategia Nacional de Inclusión in Spanish) was implemented with the objective of eradicate hunger and provide an adequate nutrition among the poorest ${ }^{(26)}$. As a result, half of the households in moderate or severe food insecurity have been included in a food aid programme ${ }^{(26)}$. Consequently, the need for updated and continuous evidence of the impact of such interventions has been noted ${ }^{(26)}$. Therefore, it is relevant to analyse the results from nutrition surveys periodically. In this study, we examined information from ENSANUT MC 2016 with the objective of further shading light on the relationship between household food insecurity and overweight, obesity and abdominal obesity in Mexican adults.

\section{Methods}

\section{Data and design}

We analysed open-access data from ENSANUT MC $2016^{(27)}$, a probabilistic survey with both regional and national representation, which included urban and rural areas from the four regions of Mexico: North, Central, Mexico City and South. A detailed description of its design has been published elsewhere ${ }^{(28)}$. Briefly, the survey gathered information from 9479 households. In all of them, the head of the family and its members were interviewed face to face by trained personnel following structured questionnaires regarding household characteristics, health and nutritional situation ${ }^{(28)}$. Questionnaires regarding sociodemographic characteristics and food insecurity were answered by the head of the household and provide household-level information ${ }^{(21,28)}$. Anthropometric measurements, semi-quantitative FFQSFFQ and physical activity, sedentariness and sleeping time questionnaires were obtained directly from the household members included in the subsamples for such questionnaires ${ }^{(21,28)}$.

Our population of interest was adults (20-59 years old). According to ENSANUT, an adult is an individual of 20 years or more ${ }^{(21)}$, and according to the National Institute of Statistic and Geography (INEGI for its acronym in Spanish, Instituto Nacional de Estadística y Geografia), 
in Mexico, a subject of 60 years or more is considered an older adult ${ }^{(29)}$. Only subjects with complete data on the above-mentioned questionnaires were included in the present study. The number of subjects whose information was available for each of our variables is presented in the following sections. A maximum of one adult per household counted with complete questionnaires. Lactating and pregnant women, as well as subjects whose information on BMI, energy consumption or physical activity was out of the valid cut-off points (specified later in the variables description section), were excluded from the study.

Based on available data for the variables included in the multivariate models and after applying the exclusion criteria, the final sample was composed of 5456 subjects representing 45804210 adult individuals at the national level. Analyses were conducted for men and women both together and separately.

\section{Exposure variable}

The household food insecurity level was the independent variable used in the present study. This variable was measured employing the Latin American and Caribbean Food Security Scale (ELCSA for its acronym in Spanish, Escala Latinoamericana y Caribeña de Seguridad Alimentaria), a validated method for evaluating household food insecurity, from the access dimension, in the Mexican population $^{(30,31)}$. ELCSA inquires about household food insecurity-related experiences during the 3 months previous to the survey ${ }^{(3)}$. It contains fifteen questions designed to be answered in a dichotomous way (yes or no) ${ }^{(3)}$. Answers are coded ' 1 ' for yes and ' 0 ' for no, generating a score that is subsequently used to classify households into one of four categories: food secure, mildly food insecure, moderately food insecure and severely food insecure ${ }^{(3)}$. Information on this variable was available for 9019 households.

For the analyses, participants were considered to inhabit either a food secure or a mildly, moderately or severely food-insecure household. Given that ELCSA was applied at a household level ${ }^{(30,31)}$, individual-specific experiences within the household might not be reflected.

\section{Outcome variables}

BMI (in $\mathrm{kg} / \mathrm{m}^{2}$ ) and waist circumference (WC, in $\mathrm{cm}$ ) were initially analysed as continuous variables. Afterwards, adults were classified either overweight or obese according to the WHO criteria with $\mathrm{BMI} \geq 25 \mathrm{~kg} / \mathrm{m}^{2}$ and $\geq 30 \mathrm{~kg} / \mathrm{m}^{2}$, respectively ${ }^{(32)}$. The range for valid $\mathrm{BMI}$ measurements was considered from 10 to $58 \mathrm{~kg} / \mathrm{m}^{2}$, as presented in previous studies for the same population of interest ${ }^{(11,21)}$. Previous to this study, the database of anthropometric information was reviewed and outliers were excluded from it by the INSP. This database showed a range of $12 \cdot 13-56.78 \mathrm{~kg} / \mathrm{m}^{2}$ for BMI, and no participants were excluded by the authors provided this criterion. Abdominal obesity was defined according to the International Diabetes Federation with a $\mathrm{WC} \geq 80 \mathrm{~cm}$ for women and $\geq 90 \mathrm{~cm}$ for $\mathrm{men}^{(21)}$. For our population of interest, there was information available on BMI of 6412 participants and WC of 6160 individuals. Anthropometric measurements taken to calculate these variables were performed applying Lohman's techniques $^{(33)}$ and the Habicht procedure for standardising fieldwork $^{(34)}$, ensuring the quality of the data collected. Height, weight and WC were measured twice, and the average was reported and used for the analyses.

\section{Covariates}

Socio-demographic characteristics

It includes age (in years); indigenous ethnicity (yes or no, depending on whether they recognised themselves as indigenous and whether they reported using an indigenous language ${ }^{(11)}$ ); educational level (preschool or none, primary or secondary education, or high school or higher); marital status (single/divorced/widow, or married/cohabitating); the number of people residing in the household (1$2,3-4,5$ or more); area of residence (urban or rural); region of the country (North, Central, Mexico City or South ${ }^{(28)}$ ); and socio-economic level (quintiles). For the latter, we took the existent classification presented by the INSP in the databases of ENSANUT MC 2016. The construction of this variable was based on a wellness condition index created using the principal components analysis method and the information collected from the socio-demographic questionnaire included in the survey ${ }^{(11)}$. The household aspects considered for developing this index were the construction materials of floor, walls and ceiling, number of rooms used for sleeping, access to water, vehicle possession, number of domestic goods and number of electronic devices ${ }^{(11)}$. Finally, the index was divided by quintiles; the first quintile $\left(Q_{1}\right)$ represents the lowest socio-economic level, and the last one $\left(\mathrm{Q}_{5}\right)$, the highest ${ }^{(11)}$. Information on these variables was available for all the subjects from the 9479 households.

\section{Energy consumption}

It is calculated from the SFFQ included in the survey. This SFFQ has been designed and validated to estimate energy, macronutrients and micronutrients consumption in Mexican adults ${ }^{(35)}$. It includes a list of 140 food and beverage items and inquires about their consumption in terms of $\mathrm{d} /$ week, times a day, portions/time and portion size ${ }^{(35)}$. Individuals in which the ratio of energy intake/estimated energy requirement was over $3 \mathrm{SD}$, or in which the ratio of energy intake/BMR was under 0.5, were excluded ${ }^{(36)}$. The extended methodology for estimating dietary data from this SFFQ has been published elsewhere ${ }^{(36)}$. There was information on this variable of 6511 subjects from our population of interest. 


\section{Physical activity}

ENSANUT MC 2016 incorporated the short version of the International Physical Activity Questionnaire. This instrument asks about the execution and duration of different physical activities performed in bouts of at least ten continuous minutes during the last $7 \mathrm{~d}^{(21)}$. Data cleaning and classification of physical activity levels were done in agreement with the International Physical Activity Questionnaire guidelines. In accordance, subjects may have a low, moderate or high level of physical activity. This classification depends on the MET-min/week, and the $\mathrm{d} /$ week, the physical activities were performed ${ }^{(37)}$. For our population of interest, there was information available on this variable for 6435 subjects.

\section{Sleeping time}

For sleeping time sufficiency classification, we applied the criteria of the US National Sleep Foundation. Accordingly, sleeping time was considered as sufficient with at least $7 \mathrm{~h} /$ $\mathrm{d}^{(38)}$. For our population of interest, there was information available on this variable for 6416 subjects.

\section{Statistical analysis}

Continuous variables are presented as means and categorical variables as proportions. Bivariate contingency tables were generated for observing the distribution of food insecurity by socio-demographic characteristics, and $\chi^{2}$ tests were performed to detect associations between these variables. Subsequently, all analyses were performed independently for men and women. Prevalences of overweight, obesity and abdominal obesity were calculated by gender and food insecurity levels. Differences in mean BMI and WC by food insecurity level were evaluated through ANOVA in conjunction with Bonferroni post-hoc testing, following confirmation of homogeneity of the variances using the Levene's test. Afterwards, the OR for overweight, obesity and abdominal obesity were obtained through bivariate and multivariate logistic regression models adjusting for multiple contrasts. For the regression analyses, the backward elimination method was employed until all covariates had a $P<0 \cdot 15^{(39)}$. Although energy consumption, physical activity level, socio-economic level and educational level were not significantly associated with the outcome variables in some models, these variables were incorporated into the analyses due to their physiological or theoretical relationship with body weight. The analyses were conducted using the complex samples option of IBM SPSS Statistics for Windows, v. 25.0. Results were reported as significant with a $P<0.05$.

\section{Results}

From the final sample, $46.7 \%$ of the subjects were males and $53.3 \%$ females. Regarding household food insecurity level, $29.2 \%$ (95\% CI 26.9\%, 31.7\%) were household-food secure, $40.7 \%$ (95\% CI 38.3\%, 43.2\%) mildly householdfood insecure, $18.8 \%$ (95\% CI 17.1\%, 20.7\%) moderately household-food insecure and 11.2\% (95\% CI 9.9\%, 12.7\%) severely household-food insecure. Household food insecurity distribution by socio-demographic characteristics is reported in Table 1.

The prevalence of overweight was 39.5\% (95\% CI $37 \cdot 2 \%, 41.8 \%)$. Men showed a higher prevalence of overweight than women $(42.8 \% v .36 .6 \% ; P<0.001)$. Obesity was present in $34.0 \%$ (95\% CI 31.7\%, 36.3\%), with higher proportion in females $(38.7 \% v$. 28.6\%; $P<0.001)$. Abdominal obesity was found in $76.4 \%$ of the sample (95\% CI $74.2 \%, 78.5 \%$ ), with also a higher prevalence among females $(87.2 \% v .64 \cdot 1 \% ; P<0.001)$. No significant associations were found between household-food insecurity and overweight, obesity or abdominal obesity among males. However, in females, the $\chi^{2}$ test showed a significant association in the case of obesity (Table 2), and mean BMI and WC were higher as household-food insecurity increased $(P<0.001)$ as shown in Fig. $1 \mathrm{a}$ and b, respectively.

Bivariate logistic regression results for the relationship between household food insecurity level, covariates and overweight, obesity and abdominal obesity among women are found in Table 3. The association between severe household-food insecurity and obesity, age, being married or cohabitating with a partner, having a primary or secondary educational level and reporting insufficient sleeping time remained significant in multivariate logistic regression models (Table 4). The relationships between severe household-food insecurity and overweight and abdominal obesity were found to be not statistically significant in multivariate models.

\section{Discussion}

Through this cross-sectional study, a positive relationship between severe household-food insecurity and obesity among Mexican women was confirmed. After controlling for covariates, obesity was twice as probable to appear in severely household-food insecure women than in household-food secure ones, although this result does not suggest a causal relationship. Additionally, mean BMI and WC were higher with higher levels of household food insecurity.

Likewise, data from 2012 showed an association between mild food insecurity and obesity among Mexican women $^{(11)}$; and mild and moderate food insecurity was related to higher odds of overweight and obesity ${ }^{(10)}$. Such findings were attributed to the consumption of foods rich in fat, sugar and refined flours, as a response to the lack of economic access of food-insecure people to healthy and more diverse diets ${ }^{(10,11)}$. Although our analyses did not 
Table 1 Household food insecurity distribution according to socio-demographic characteristics of the population. Mexican adults (20-59 years old). ENSANUT MC 2016

\begin{tabular}{|c|c|c|c|c|c|c|c|c|c|c|}
\hline & \multirow[b]{2}{*}{$n$} & \multicolumn{2}{|c|}{$\begin{array}{l}\text { Household food } \\
\text { secure }\end{array}$} & \multicolumn{2}{|c|}{$\begin{array}{l}\text { Mildly household- } \\
\text { food insecure }\end{array}$} & \multicolumn{2}{|c|}{$\begin{array}{l}\text { Moderately } \\
\text { household-food } \\
\text { insecure }\end{array}$} & \multicolumn{2}{|c|}{$\begin{array}{l}\text { Severely house- } \\
\text { hold-food } \\
\text { insecure }\end{array}$} & \multirow[b]{2}{*}{$P$} \\
\hline & & $\%$ & $95 \% \mathrm{Cl}$ & $\%$ & $95 \% \mathrm{Cl}$ & $\%$ & $95 \% \mathrm{Cl}$ & $\%$ & $95 \% \mathrm{Cl}$ & \\
\hline \multicolumn{10}{|l|}{ Sex } & 0.613 \\
\hline Women & 1807 & $29 \cdot 8$ & $26 \cdot 7,33 \cdot 3$ & 41.4 & $38.4,44.5$ & $17 \cdot 7$ & $15 \cdot 6,20 \cdot 0$ & 11.0 & $9 \cdot 5,12 \cdot 8$ & \\
\hline Men & 3649 & 28.5 & $25 \cdot 1,32 \cdot 2$ & 39.9 & $36 \cdot 3,43 \cdot 6$ & $20 \cdot 1$ & $17 \cdot 3,23 \cdot 3$ & 11.4 & $9 \cdot 2,14 \cdot 2$ & \\
\hline \multicolumn{10}{|l|}{ Age group (years) } & 0.637 \\
\hline $20-29$ & 1242 & $31 \cdot 7$ & $27 \cdot 5,36 \cdot 3$ & 38.7 & $34.7,42 \cdot 9$ & $17 \cdot 7$ & $14 \cdot 4,21 \cdot 7$ & 11.8 & $8.9,15.5$ & \\
\hline $30-39$ & 1589 & $28 \cdot 8$ & $24 \cdot 7,33 \cdot 3$ & 43.2 & $38 \cdot 3,48 \cdot 1$ & $18 \cdot 3$ & $15 \cdot 1,22 \cdot 0$ & $9 \cdot 7$ & $7 \cdot 6,12 \cdot 3$ & \\
\hline $40-49$ & 1457 & $29 \cdot 0$ & $24 \cdot 7,33 \cdot 7$ & $39 . \overline{5}$ & $35.8,43.2$ & $20 \cdot 1$ & $16 \cdot 7,23 \cdot 9$ & 11.5 & $8 \cdot 9,14 \cdot 7$ & \\
\hline $50-59$ & 1168 & $25 \cdot 7$ & $21 \cdot 4,30 \cdot 5$ & 42.4 & $38 \cdot 1,46 \cdot 8$ & 19.9 & $16 \cdot 4,24 \cdot 0$ & $12 \cdot 0$ & $9 \cdot 2,15 \cdot 6$ & \\
\hline \multicolumn{10}{|l|}{ Indigenous ethnicity } & $<0.001$ \\
\hline No & 4862 & 30.4 & $27 \cdot 9,33 \cdot 0$ & 40.5 & $37 \cdot 9,43 \cdot 1$ & 18.4 & $16 \cdot 7,20 \cdot 3$ & $10 \cdot 7$ & $9 \cdot 3,12 \cdot 3$ & \\
\hline Yes & 594 & $12 \cdot 3$ & $7 \cdot 9,18 \cdot 8$ & 44.0 & $36 \cdot 4,51 \cdot 8$ & $25 \cdot 0$ & $18 \cdot 3,33 \cdot 2$ & $18 \cdot 6$ & $12 \cdot 1,27 \cdot 6$ & \\
\hline \multicolumn{10}{|l|}{ Education level } & $<0.001$ \\
\hline High school or higher & 1439 & $40 \cdot 2$ & $35 \cdot 5,45 \cdot 2$ & 37.9 & $33 \cdot 9,42 \cdot 0$ & $14 \cdot 2$ & $11 \cdot 6,17 \cdot 3$ & $7 \cdot 7$ & $5 \cdot 8,10 \cdot 1$ & \\
\hline Elementary or secondary & 3683 & $22 \cdot 3$ & $20 \cdot 0,24 \cdot 7$ & $43 \cdot 1$ & $40 \cdot 1,46 \cdot 1$ & $21 \cdot 6$ & $19 \cdot 2,24 \cdot 2$ & $13 \cdot 0$ & $11 \cdot 2,15 \cdot 0$ & \\
\hline Preschool or none & 334 & $18 \cdot 7$ & $11 \cdot 4,28 \cdot 9$ & $35 \cdot 2$ & $26 \cdot 1,45 \cdot 5$ & 24.7 & $17 \cdot 8,33 \cdot 1$ & 21.5 & 13.7. $32 \cdot 0$ & \\
\hline \multicolumn{10}{|l|}{ Marital status } & 0.485 \\
\hline Single/divorced/widow & 1645 & 28.9 & $25 \cdot 1,32 \cdot 9$ & $40 \cdot 1$ & $35 \cdot 7,44 \cdot 6$ & $18 \cdot 2$ & $15 \cdot 2,21 \cdot 6$ & $12 \cdot 8$ & $10 \cdot 5,15 \cdot 6$ & \\
\hline Married/cohabitating & 3811 & $29 \cdot 4$ & $26 \cdot 6,32 \cdot 4$ & $41 \cdot 0$ & $38.4,43 \cdot 8$ & $19 \cdot 1$ & $17 \cdot 2,21 \cdot 3$ & $10 \cdot 4$ & $8 \cdot 7,12 \cdot 3$ & \\
\hline \multicolumn{10}{|c|}{ Number of people residing in the household } & 0.014 \\
\hline $1-2$ & 1786 & 31.9 & $28 \cdot 4,35 \cdot 8$ & $38 \cdot 8$ & $35 \cdot 4,42 \cdot 2$ & $20 \cdot 3$ & $17 \cdot 4,23 \cdot 6$ & 8.9 & $7 \cdot 4,10 \cdot 8$ & \\
\hline $3-4$ & 2376 & $30 \cdot 4$ & $26 \cdot 6,34 \cdot 4$ & 41.9 & $38 \cdot 4,45 \cdot 4$ & $18 \cdot 0$ & $15 \cdot 5,20 \cdot 9$ & $9 \cdot 7$ & $7.9,11.9$ & \\
\hline 5 or more & 1294 & $25 \cdot 8$ & $21 \cdot 8,30 \cdot 2$ & $40 \cdot 4$ & $35 \cdot 5,45 \cdot 6$ & $18 \cdot 9$ & $15 \cdot 6,22 \cdot 6$ & 14.9 & $12 \cdot 1,18 \cdot 3$ & \\
\hline \multicolumn{10}{|l|}{ Residence area } & $<0.001$ \\
\hline Rural & 2774 & $21 \cdot 7$ & $18 \cdot 8,25 \cdot 0$ & $47 \cdot 8$ & $44 \cdot 6,51 \cdot 0$ & $19 \cdot 8$ & $17 \cdot 2,22 \cdot 8$ & $10 \cdot 6$ & $8 \cdot 7,12.9$ & \\
\hline Urban & 2682 & $31 \cdot 7$ & $28 \cdot 7,34 \cdot 8$ & 38.4 & $35.5,41.5$ & 18.5 & $16 \cdot 4,20 \cdot 8$ & $11 \cdot 4$ & $9 \cdot 7,13 \cdot 3$ & \\
\hline \multicolumn{10}{|l|}{ Region of the country } & 0.010 \\
\hline Centre & 1424 & $28 \cdot 3$ & $23 \cdot 8,33 \cdot 4$ & $44 \cdot 2$ & $39 \cdot 3,49 \cdot 2$ & $16 \cdot 9$ & $14 \cdot 2,19 \cdot 9$ & $10 \cdot 5$ & $8 \cdot 1,13 \cdot 7$ & \\
\hline Mexico City & 599 & $32 \cdot 2$ & $26 \cdot 3,38 \cdot 9$ & 35.4 & $30.4,40.9$ & 21.4 & $16 \cdot 9,26 \cdot 7$ & 10.9 & $7 \cdot 9,14.9$ & \\
\hline North & 1714 & $34 \cdot 3$ & $29 \cdot 6,39.2$ & $37 \cdot 6$ & $33 \cdot 1,42 \cdot 4$ & $16 \cdot 4$ & $13 \cdot 3,20 \cdot 0$ & 11.8 & $9.5,14.5$ & \\
\hline \multirow{2}{*}{\multicolumn{10}{|c|}{ Socio-economic level }} & \\
\hline & & & & & & & & & & $<0.001$ \\
\hline$Q_{5}$ & 1051 & $43 \cdot 1$ & $38 \cdot 3,48 \cdot 0$ & $40 \cdot 1$ & $35 \cdot 6,44.9$ & $12 \cdot 6$ & $9 \cdot 4,16 \cdot 6$ & $4 \cdot 2$ & $2 \cdot 9,6 \cdot 2$ & \\
\hline$Q_{4}$ & 1073 & $28 \cdot 7$ & $24 \cdot 6,33 \cdot 2$ & $42 \cdot 0$ & $37 \cdot 6,46 \cdot 5$ & $17 \cdot 4$ & $14 \cdot 2,21 \cdot 1$ & 11.9 & $8 \cdot 7,16 \cdot 0$ & \\
\hline$Q_{3}$ & 1112 & $26 \cdot 3$ & $21 \cdot 4,31 \cdot 9$ & 37.0 & $32 \cdot 0,42 \cdot 2$ & 23.4 & $19 \cdot 5,27 \cdot 8$ & $13 \cdot 3$ & $10 \cdot 0,17 \cdot 5$ & \\
\hline$Q_{2}$ & 1126 & $17 \cdot 1$ & $14 \cdot 0,20 \cdot 6$ & $42 \cdot 1$ & $37 \cdot 3,47 \cdot 1$ & $23 \cdot 2$ & $19 \cdot 5,27 \cdot 3$ & $17 \cdot 7$ & $13 \cdot 5,22 \cdot 7$ & \\
\hline$Q_{1}$ & 1094 & $11 \cdot 2$ & $8.5,14.8$ & $43 \cdot 7$ & $38.7,48.9$ & $26 \cdot 8$ & $21 \cdot 7,32 \cdot 6$ & $18 \cdot 3$ & $13 \cdot 8,23 \cdot 8$ & \\
\hline
\end{tabular}

$\mathrm{Q}_{\mathrm{i}}$, quintile and quintile number $\left(\mathrm{Q}_{5}\right.$ represents the highest socio-economic level).

$P$-values correspond to the $\chi^{2}$ test of independence for each variable and food insecurity level.

Table 2 Overweight, obesity and abdominal obesity prevalence by household food insecurity level in Mexican women. ENSANUT MC 2016

\begin{tabular}{|c|c|c|c|c|c|c|c|c|}
\hline & \multicolumn{2}{|c|}{$\begin{array}{l}\text { Household food } \\
\text { security }\end{array}$} & \multicolumn{2}{|c|}{$\begin{array}{l}\text { Mild household-food } \\
\text { insecurity }\end{array}$} & \multicolumn{2}{|c|}{$\begin{array}{l}\text { Moderate household- } \\
\text { food insecurity }\end{array}$} & \multicolumn{2}{|c|}{$\begin{array}{l}\text { Severe household-food } \\
\text { insecurity }\end{array}$} \\
\hline & $\%$ & $95 \% \mathrm{Cl}$ & $\%$ & $95 \% \mathrm{Cl}$ & $\%$ & $95 \% \mathrm{Cl}$ & $\%$ & $95 \% \mathrm{Cl}$ \\
\hline Overweight & 34.46 & $29 \cdot 78,39 \cdot 46$ & 39.38 & $35.42,43.48$ & 34.96 & $29 \cdot 79,41 \cdot 69$ & 34.74 & $26.76,43 \cdot 68$ \\
\hline Obesity* & $35 \cdot 31$ & $30 \cdot 47,40 \cdot 47$ & 36.85 & $32 \cdot 59,41 \cdot 32$ & $42 \cdot 26$ & $35 \cdot 66,49 \cdot 14$ & $49 \cdot 13$ & $40.55,57.77$ \\
\hline Abdominal obesity & 86.89 & $82.89,89.90$ & 85.94 & $82 \cdot 38,88 \cdot 88$ & 86.92 & $82 \cdot 13,90.57$ & 93.24 & $88.24,96 \cdot 21$ \\
\hline
\end{tabular}

${ }^{\star} P=0.023$ from the $\chi^{2}$ test of independence.

show a significant relationship with mild and moderate household-food insecurity, a similar trend was observed.

Resembling our findings, severe food insecurity was associated with a greater likelihood of obesity in lowincome Latino women in California ${ }^{(6)}$. This relationship was explained by a possible occurrence of cycles of involuntary food restriction followed by overeating periods ${ }^{(6)}$, a situation that was also reported in $2009^{(9)}$. This condition could trigger a metabolic response for increasing the body's efficiency for storing energy in the form of fat ${ }^{(6)}$.

Similarly, in Brazil, severe food insecurity was related to excessive weight in female adolescents ${ }^{(12)}$. Back then, it was suggested that this condition might result from energy overconsumption incentivised by the affordability of energy-dense foods, as can occur at certain stages of the nutritional transition in a country ${ }^{(12)}$. Additionally, it was 
(a)

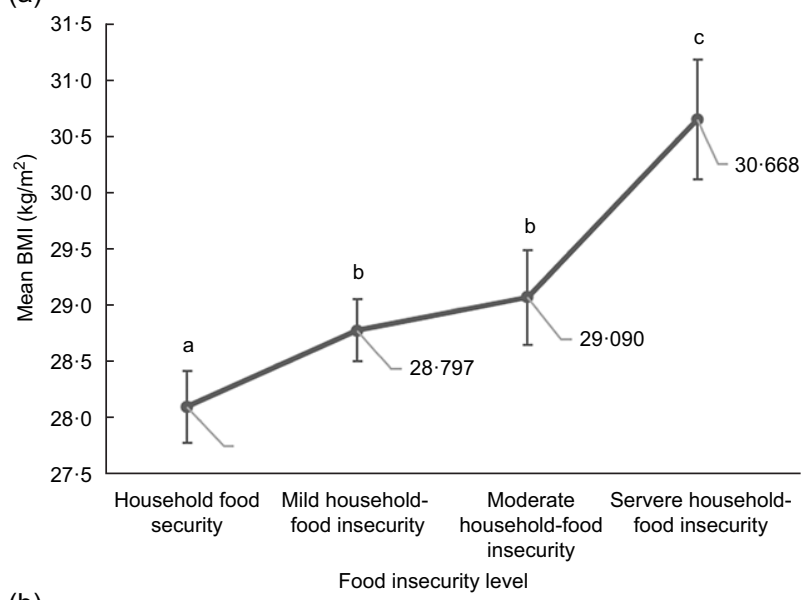

(b)

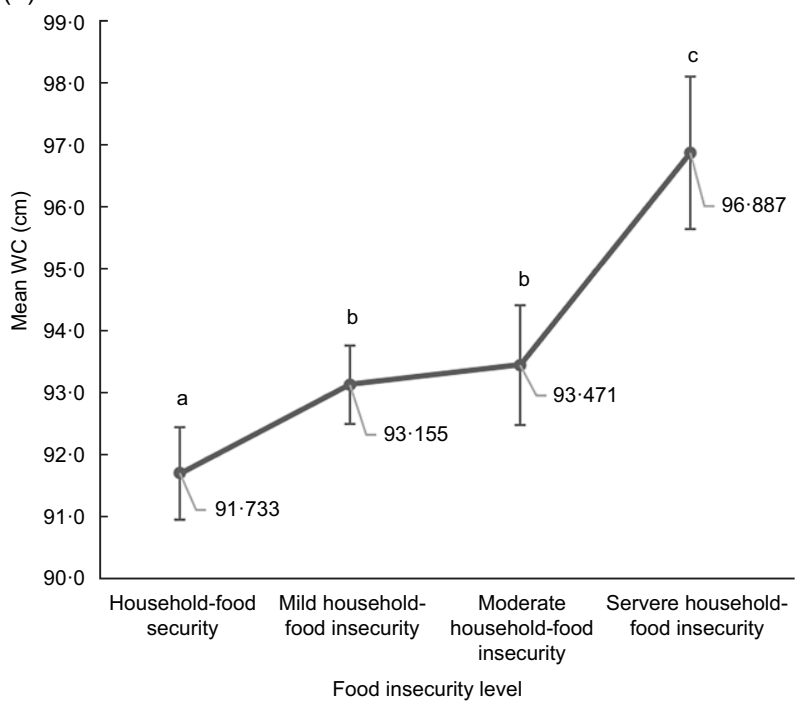

Fig. 1 Mean BMI (a) and WC (b) by food insecurity level in Mexican women ( $n$ 3649). Error bars represent the $95 \% \mathrm{Cl}$ of the mean based on the standard error. Significant differences $(P<0.05)$ between food security levels are indicated with dissimilar letters. WC, waist circumference

also mentioned that participating in cash-transfer programmes might be a risk factor for overweight given the insufficiency of the monetary support for lasting the whole month, which would lead families to stretch their budgets and relying on low-cost, high-calorie foods ${ }^{(12)}$.

From the analyses of continuous variables, we observed higher mean BMI with higher levels of household-food insecurity. This is comparable to what has been reported in Costa Rica, where it was described that BMI was positively correlated with any level of food insecurity ${ }^{(13)}$. In that context, elevated food prices, seasonal unemployment and abandonment of agricultural activities were found to be the main determinants for such observations ${ }^{(13)}$. Those factors affected people's diet by leading to increases in the consumption of staples, processed meats and cheeses, and fried snacks while reducing the purchase of more expensive products such as fruits and vegetables ${ }^{(13)}$.
Regarding our evaluation of WC and abdominal obesity, we included these indicators of visceral fat for being better predictors of cardiometabolic risk and mortality than $\mathrm{BMI}^{(40)}$. We found significantly higher levels of mean WC with higher household-food insecurity, and a higher proportion of abdominal obesity among severely householdfood insecure women. However, the association between household-food insecurity and abdominal obesity was not significant in multivariate models. This discrepancy might be explained by either the strikingly high and generalised prevalence of the latter among the population or because of the higher sensitivity of the analysis conducted with continuous variables. Other studies have reported findings similar to ours. For instance, in Malaysia, abdominal obesity prevalence was higher among food-insecure women, which was attributed to the consumption of low-diverse diets and physical inactivity ${ }^{(41)}$. Similarly, in $\operatorname{Iran}^{(42)}$ and Brazil $^{(14)}$, it has been observed that abdominal obesity is more likely to occur in severe food insecurity situations, but a causal association has not been established.

From a biological perspective, the food insecurityobesity paradox has been explained through the resource scarcity hypothesis ${ }^{(17)}$. Accordingly, food insecurity in an environment where high-calorie foods are more accessible than healthier foods may especially affect individuals of lower social status ${ }^{(17)}$. Aside from their limited purchasing power, which might restraint their food choices, in this segment of the population, individuals have lower fat oxidation and metabolic rates ${ }^{(17,43)}$, and higher concentrations of serum cortisol ${ }^{(44)}$, which has been associated with leptin and insulin resistance, thereby promoting fat accumulation $^{(17,45)}$. Additionally, poverty and the fact of living in an adverse environment can lead to an increased desire for food and to opting for consuming high amounts of energy-dense products (binging), probably due to the perception that food supply is inadequate or that access to it might be compromised in the future ${ }^{(46)}$.

Interestingly, the majority of studies that have analysed the association between food insecurity and obesity report positive results more frequently among females than males. The above has been explained by a number of arguments indicating that women might have: (i) periods of increased food intake due to greater anxiety and social stress ${ }^{(17,47)}$, (ii) a lower economic capacity to achieve food security ${ }^{(48)}$, (iii) a lower physical activity level ${ }^{(48)}$, (iv) a physiological response for ensuring adequate body fat levels for reproduction $^{(17,49)}$ or (v) due to probable unequal food distribution at the household level ${ }^{(6,15)}$, which can occur in response to protecting children from the adverse effects of food insecurity ${ }^{(12)}$. This last hypothesis has been suggested for rural and indigenous Mexican populations, where males, as the primary workforce, have priority in feeding, leaving children and women at a disadvantage $^{(15)}$. However, more studies on this maternal buffering response are required. 
Table 3 Bivariate logistic regression models for the associations between household food insecurity and overweight, obesity and abdominal obesity in Mexican women. ENSANUT MC 2016

\begin{tabular}{|c|c|c|c|c|c|c|c|c|c|}
\hline \multirow[b]{2}{*}{ Variable } & \multicolumn{3}{|c|}{ Overweight } & \multicolumn{3}{|c|}{ Obesity } & \multicolumn{3}{|c|}{ Abdominal obesity } \\
\hline & OR & $95 \% \mathrm{Cl}$ & $P$ & OR & $95 \% \mathrm{Cl}$ & $P$ & OR & $95 \% \mathrm{Cl}$ & $P$ \\
\hline \multicolumn{10}{|l|}{ Household food insecurity level } \\
\hline Household food security & 1.00 & & & 1.00 & & & 1.00 & & \\
\hline Mild household-food insecurity & 1.48 & $0.97,2.25$ & 0.068 & 1.35 & $0.87,2.09$ & 0.181 & 0.93 & $0.60,1.45$ & 0.753 \\
\hline Moderate household-food insecurity & 1.47 & $0.86,2.50$ & 0.158 & 1.73 & $1.02,2.95$ & 0.044 & 1.01 & $0.61,1.68$ & 0.963 \\
\hline Severe household-food insecurity & 1.85 & $1.08,3.16$ & 0.025 & 2.55 & $1.54,4.23$ & $<0.001$ & $2 \cdot 10$ & $1.08,4 \cdot 10$ & 0.029 \\
\hline \multicolumn{10}{|l|}{ Indigenous ethnicity } \\
\hline No & 1.00 & & & 1.00 & & & 1.00 & & \\
\hline Yes & $1 \cdot 16$ & $0.63,2.13$ & 0.642 & 0.71 & $0.41,1.24$ & 0.227 & 0.78 & $0.38,1.62$ & 0.507 \\
\hline \multicolumn{10}{|l|}{ Education level } \\
\hline High school or higher & 1.00 & & & 1.00 & & & 1.000 & & \\
\hline Elementary or secondary & 1.31 & $0.93,1.85$ & $0 \cdot 124$ & $1 \cdot 84$ & $1 \cdot 31,2 \cdot 60$ & 0.001 & $2 \cdot 12$ & $1.52,2.94$ & $<0.001$ \\
\hline Preschool or none & 2.49 & $1 \cdot 20,5 \cdot 16$ & 0.015 & 2.57 & $1.33,4.96$ & 0.005 & $3 \cdot 71$ & $1.61,8.54$ & 0.002 \\
\hline \multicolumn{10}{|l|}{ Marital status } \\
\hline Single/divorced/widow & 1.00 & & & 1.00 & & & 1.00 & & \\
\hline Married/cohabitating & 1.32 & $0.99,1.77$ & 0.056 & 1.624 & $1 \cdot 21,2 \cdot 17$ & 0.001 & 1.57 & $1 \cdot 13,2 \cdot 18$ & 0.008 \\
\hline \multicolumn{10}{|c|}{ Number of people residing in the household } \\
\hline $1-2$ & 1.00 & & & 1.00 & & & 1.00 & & \\
\hline $3-4$ & 0.81 & $0.60,1.09$ & 0.154 & 0.74 & $0.52,1.05$ & 0.089 & 0.98 & $0.69,1.39$ & 0.905 \\
\hline 5 or more & $1 \cdot 12$ & $0.77,1.64$ & 0.554 & 0.79 & $0.52,1.19$ & 0.260 & $1 \cdot 17$ & $0.76,1.79$ & 0.486 \\
\hline \multicolumn{10}{|l|}{ Residence area } \\
\hline Rural & 1.00 & & & 1.00 & & & 1.00 & & \\
\hline Urban & 0.88 & $0.68,1.15$ & 0.339 & 1.04 & $0.80,1.35$ & 0.760 & 0.94 & $0.69,1.29$ & 0.708 \\
\hline \multicolumn{10}{|l|}{ Region of the country } \\
\hline Centre & 1.00 & & & 1.00 & & & 1.00 & & \\
\hline Mexico City & 1.45 & $0.94,2.25$ & 0.096 & 1.33 & $0.86,2.05$ & 0.20 & 1.05 & $0.63,1.76$ & 0.849 \\
\hline North & 1.21 & $0.84,1.74$ & 0.306 & 1.33 & $0.89,1.99$ & 0.16 & 1.04 & $0.70,1.56$ & 0.840 \\
\hline South & 1.23 & $0.90,1.69$ & 0.190 & 1.45 & $0.98,2.16$ & 0.06 & 0.89 & $0.62,1.27$ & 0.504 \\
\hline \multicolumn{10}{|l|}{ Socio-economic level } \\
\hline $\mathrm{Q}_{5}$ & 1.00 & & & 1.00 & & & 1.00 & & \\
\hline$Q_{4}$ & 1.02 & $0.68,1.53$ & 0.932 & 1.00 & $0.68,1.48$ & 0.994 & 0.97 & $0.64,1.46$ & 0.864 \\
\hline$Q_{3}$ & 1.31 & $0.84,2.05$ & 0.234 & 1.70 & $1 \cdot 11,2 \cdot 60$ & 0.015 & $1 \cdot 12$ & $0.71,1.76$ & 0.634 \\
\hline$Q_{2}$ & 1.05 & $0.68,1.63$ & $0 \cdot 814$ & $1 \cdot 11$ & $0.71,1.72$ & 0.653 & 0.83 & $0.51,1.35$ & 0.447 \\
\hline$Q_{1}$ & 1.06 & $0.68,1.66$ & 0.787 & 0.99 & $0.63,1.57$ & 0.990 & 0.85 & $0.53,1.34$ & 0.474 \\
\hline \multicolumn{10}{|l|}{ Physical activity level } \\
\hline High & 1.00 & & & 1.00 & & & 1.00 & & \\
\hline Moderate & 1.00 & $0.71,1.41$ & 0.998 & 0.73 & $0.52,1.01$ & 0.057 & 0.84 & $0.58,1.20$ & 0.332 \\
\hline Low & $1 \cdot 10$ & $0.74,1.64$ & 0.636 & $1 \cdot 10$ & $0.74,1.63$ & 0.648 & 0.90 & $0.58,1.38$ & 0.614 \\
\hline \multicolumn{10}{|l|}{ Sleeping time } \\
\hline Sufficient & 1.00 & & & 1.00 & & & 1.00 & & \\
\hline Insufficient & 1.39 & $0.96,2.01$ & 0.081 & 1.86 & $1.33,2.59$ & $<0.001$ & 1.98 & $1 \cdot 38,2 \cdot 85$ & $<0.001$ \\
\hline
\end{tabular}

$Q_{i}$, quintile and quintile number $\left(Q_{5}\right.$ represents the highest socio-economic level).

Other observations from this study include the associations found between insufficient sleeping time and obesity. These findings concur with clinical and experimental investigations that evidence the relevance of sleeping as a regulator of endocrine and metabolic processes. Sleeping restriction can contribute to triggering overweight and obesity $^{(50)}$. This condition has been linked to higher sensations of hunger, cravings for carbohydrate-rich food, greater ingestion of food during the night time and digestive problems ${ }^{(50)}$. On the other hand, this association could also occur in the opposite direction. An analysis from ENSANUT MC 2016 found that BMI was a predictive factor for obstructive sleep apnoea and daytime sleepiness or not restful sleep ${ }^{(51)}$. Therefore, it has been pointed out the relevance of counting with longitudinal studies that allow a better understanding of the sleep problems in Mexico and their association with obesity ${ }^{(50)}$. Moreover, that sleeping habits should be part of the interventions aimed to attend the obesity epidemic in the country ${ }^{(51)}$.

With regard to physical activity level, we did not observe a significant association with our outcome variables. Nonetheless, we suggest further studies regarding its association with obesity and abdominal obesity. As reported by previous publications, physical activity should get more attention in the fight against obesity in Mexico ${ }^{(52)}$. The National Program for Physical Culture and Sport for 20142018 reported a lack of governmental promotion and programmes for the practice of physical activity and a lack of physical activity habits by the population ${ }^{(52)}$. According to the ENSANUT MC 2016, 14.4\% of Mexican adults did not meet the WHO recommendations for minimal physical activity, being the main barriers for not practicing it lack of time, lack of adequate and safe spaces, and lack of motivation ${ }^{(21)}$. In other contexts, it has been suggested that the lack of 
Table 4 Multivariate logistic regression model for the association between household food insecurity and obesity in Mexican women. ENSANUT MC 2016

\begin{tabular}{|c|c|c|c|}
\hline & \multicolumn{3}{|c|}{ Obesity } \\
\hline & OR & $95 \% \mathrm{Cl}$ & $P$ \\
\hline \multicolumn{4}{|l|}{ Household food insecurity level } \\
\hline Household food security & 1.00 & & \\
\hline Mild household-food insecurity & 1.28 & $0.81,2.02$ & 0.299 \\
\hline Moderate household-food insecurity & 1.53 & $0.88,2.66$ & 0.133 \\
\hline Severe household-food insecurity & $2 \cdot 36$ & $1.40,3.98$ & 0.001 \\
\hline Age (years) & 1.04 & $1.02,1.05$ & $<0.001$ \\
\hline \multicolumn{4}{|l|}{ Education level } \\
\hline High school or higher & 1.00 & & \\
\hline Primary or secondary & 1.43 & $1.01,2.03$ & 0.042 \\
\hline Preschool or none & 1.44 & $0.68,3.04$ & 0.341 \\
\hline \multicolumn{4}{|l|}{ Marital status } \\
\hline Single/divorced/widow & 1.00 & & \\
\hline Married/cohabitating & 1.53 & $1 \cdot 14,2 \cdot 06$ & 0.005 \\
\hline \multicolumn{4}{|l|}{ Socio-economic level } \\
\hline$Q_{5}$ & 1.00 & & \\
\hline$Q_{4}$ & 0.92 & $0.61,1.39$ & 0.684 \\
\hline$Q_{3}$ & 2.42 & $1.54,1.98$ & 0.063 \\
\hline$Q_{2}$ & 0.83 & $0.58,1.19$ & 0.303 \\
\hline$Q_{1}$ & $1 \cdot 12$ & $0.75,1.67$ & 0.586 \\
\hline Energy consumption (kcal) & 1.00 & $1.00,1.00$ & 0.607 \\
\hline \multicolumn{4}{|l|}{ Physical activity level } \\
\hline High & 1.00 & & \\
\hline Moderate & 0.83 & $0.58,1.19$ & 0.303 \\
\hline Low & $1 \cdot 12$ & $0.75,1.67$ & 0.586 \\
\hline \multicolumn{4}{|l|}{ Sleeping time } \\
\hline Sufficient & 1.00 & & \\
\hline Insufficient & 1.86 & $1.28,2.68$ & 0.001 \\
\hline
\end{tabular}

$Q_{i}$, quintile and quintile number $\left(Q_{5}\right.$ represents the highest socio-economic level).

healthy food or the uncertainty of access to food, related to food insecurity, could lead people to be physiologically or psychologically less energetic to practice physical activity ${ }^{(53)}$. This could be another way in which food insecurity might be affecting the health and weight status of people; however, studies would be needed in the Mexican setting.

In regard to education, having only primary or secondary schooling has been associated with our outcome variables. Nonetheless, we did not observe a significant result in the case of counting with preschool or none. Other authors have reported an inverse association between education and obesity among Mexican women from urban areas but not from the rural setting, where obesity prevalence has been higher in females with secondary education than in those with primary or less, but also than those with high school or higher education ${ }^{(54)}$. In that publication, it was proposed that probably less-educated rural women had a lower economic purchasing power that might protect them for acquiring processed, high-calorie foods; nonetheless, that the increasing availability of these products at low cost in their communities might eventually revert their situation $^{(54)}$

Although our results could have a similar explanation, another possibility is that people with low academic preparation could be limited to predominantly physical occupations that prevent them from obesity (e.g. agriculture), as it has been suggested previously ${ }^{(55)}$. The relevance of education in this context lies in its influence over other social determinants of health, such as occupation and income, therefore, on the economic access to food $^{(55)}$. Furthermore, the level and quality of education are linked to greater health literacy and health behaviours ${ }^{(55)}$. For instance, it has been observed that nutritional education is more effective in higher educated people ${ }^{(55)}$.

The strengths of our study include the inclusion of abdominal fat indicators in addition to generalised obesity, and the use of a nationally representative sample for the analyses. Thus, the results are applicable nationwide, and to some extent, even to similar contexts to Mexico.

Limitations of our research refer to the inability to infer a cause-effect relationship due to its cross-sectional design. Moreover, the instruments used to assess diet and food insecurity capture information related to defined periods of time. Thereby, the season in which the survey was carried out could have influenced the responses on these variables, mainly in families that depend on their food production, as is the case in many rural areas. Additionally, the interpretation of our results could be further complemented by knowing how long people have been experiencing food insecurity. For instance, some authors have found that suffering from food insecurity in the past is related to obesity in the future ${ }^{(56)}$. Finally, given that food insecurity was a household-level measurement, and not an individual one, the particular experiences of the household members might not be reflected with exactitude in the analysis of this variable.

Furthermore, it has been reported that experiencing famine and nutritional deficiencies in prenatal and perinatal stages, and early infancy can undermine the physiological performance of the organism even until adulthood, influencing the development of obesity ${ }^{(57)}$. Additionally, our understanding of the phenomenon of study in this investigation would be clearer by knowing the individual and household coping strategies (i.e. fall-back mechanisms to face short-term insufficiency of food) and adaptative mechanisms (i.e. long-term or permanent changes in the way households and individuals acquire sufficient food or income to deal with food insufficiency) that emerge to face this situation ${ }^{(58)}$. Perhaps, longitudinal or qualitative studies might be convenient in the last case.

Another limitation of our study could be that diet was evaluated only in terms of energy intake, whereas a more detailed analysis of the SFFQ getting information on dietary diversity and quality might have been more advantageous in two aspects. First, this information is essential to provide specific food policy recommendations. Second, it might be helpful in understanding the differences observed between our findings and the reports derived from ENSANUT 2012.

At that time, mild food insecurity was associated with obesity ${ }^{(11)}$. Accordingly, the authors attributed this result to an affectation of the dietary quality, driven by the low purchasing power of the food-insecure families ${ }^{(11)}$. Since 
then, these individuals may have improved their diets or the strategies to deal with food insecurity. This hypothesis would be supported by a recent evaluation of the food assistance programmes of the last years ${ }^{(26)}$. But on the other hand, a previous study conducted in rural communities from the southern region of Mexico found that both cash transfers and food baskets contributed to increasing obesity in females ${ }^{(59)}$. The above let us point out the need for future evaluations on the health outcomes derived from food programmes, in addition to the assessments on coverage and focalisation that have been conducted ${ }^{(26)}$. These proposed studies should also contemplate the role of food programmes in potential abundance-shortage cycles in the household.

As we have confirmed in this study, household-food insecurity is part of the multiple elements that contribute to obesity in Mexico. It might be affecting people's diet by economic restraints that lead to the consumption of inexpensive calorie-dense products ${ }^{(15)}$. Moreover, it could be involved in the development of behaviours like eating disorders (binging) ${ }^{(46)}$, stress and associated hormonal imbalances ${ }^{(17)}$. The latter, in conjunction with the inconsistent access to food, poor dietary quality and the lack of healthy habits (physical activity and sleeping), could be triggering metabolic alterations that are reflected in fat and weight gain ${ }^{(6,9,50)}$.

In comparison with previous studies, our findings show that there has not been a substantial improvement in the food and nutritional problems in the last years, notwithstanding the constitutional reforms and programmatic interventions on these aspects ${ }^{(25)}$. Given the magnitude of the circumstances, the government and society should consider these problems more seriously and confront them urgently. Our observations are a reflection of the economic inequalities that have existed and persist in Mexico and highlight the need for attending the current food insecurity and obesity challenges from the root. Therefore, the health, educational and economic sectors of the country should respond collectively with even stronger efforts to overcome the current health crisis.

As it has been previously said, the approach to food insecurity and obesity should contemplate a structural perspective ${ }^{(11)}$. While assistance programmes should maintain and increase their progress in coverage and inclusion ${ }^{(26)}$, other interventions should work on ensuring sustainable and long-term impacts on the availability of healthier foods, assuring permanent economic access to these, and increasing awareness in the population about the adoption of healthy diets and lifestyles. The consistency and permanence of government programmes directed to alleviate hunger and to improve people's nutritional status should be guaranteed, prioritising the most vulnerable population sectors (females, indigenous groups, rural areas, the southern region of the country, people of low educational and socio-economic level).

\section{Acknowledgements}

Acknowledgements: The authors thank Lucía Cuevas Nasu, Brenda Martínez Tapia, Sonia Rodríguez Ramírez, Catalina Medina García, Martín Romero Martínez and Ignacio Méndez-Gomez Humarán, from the Mexican National Institute of Public Health (INSP), for their aid and clarifications in the handling of the information from the survey. The authors also acknowledge the work of the INSP in conducting the ENSANUT MC 2016 and making available the data. Financial support: This research received no specific grant from any funding agency, commercial or not-for-profit sectors. Conflict of interest: The authors declare no conflict of interest. Authorship: R.E.P.A. formulated the research questions and designed the study, managed the data set, conducted the statistical analyses and wrote the manuscript. J.L.R.G.L. provided guidance on the statistical analysis. T.S.L. and H.M.Q. provided orientation, counseling and feedback through all the research process. All the authors read, contributed to and approved the final manuscript. Ethics of buman subject participation: This study analysed open-access data from the Mexican Halfway National Health and Nutrition Survey 2016. This survey was conducted according to the guidelines laid down in the Declaration of Helsinki, and all procedures involving human subjects were approved by the Ethics, Research and Biosafety commissions of the National Public Health Institute in Mexico, and reviewed by the General Direction of Epidemiology of the Health Ministry in Mexico. Written informed consent was obtained from all subjects participating in the survey.

\section{References}

1. Napoli M, De Muro P \& Mazziotta M (2010) Towards a Food Insecurity Multidimensional Index (FIMI). Roma: Roma Tre, Universita Degli Studi; available at http://www.fao.org/ fileadmin/templates/ERP/uni/FIMI.pdf (accessed June 2021).

2. Food and Agriculture Organization of the United Nations (1997) Food Insecurity and Vulnerability Information and Mapping Systems. Rome: FAO.

3. Comité Científico de la ELCSA (2012) Escala Latino Americana y Caribeña de Seuridad Alimentaria (ELCSA). Manual de Uso y Aplicación (Latin American and Caribbean Food Security Scale (ELCSA). Use and Application Manual). Rome: Food and Agriculture Organization of the United Nations (FAO).

4. Goldblatt PB, Moore ME \& Stunkard AJ (1965) Social factors in obesity. JAMA 192, 1039-1044.

5. Dietz WH (1995) Does hunger cause obesity? Pediatrics $\mathbf{9 5}$, 766-767.

6. Kaiser LL, Townsend MS, Melgar-Quiñonez HR et al. (2004) Choice of instrument influences relations between food insecurity and obesity in Latino women. Am J Clin Nutr 80, $1372-1378$.

7. Papas MA, Trabulsi JC, Dahl A et al. (2016) Food insecurity increases the odds of obesity among young Hispanic children. J Immigr Minor Health 18, 1046-4052. 
8. Seligman HK, Laraia BA \& Kushel MB (2009) Food insecurity is associated with chronic disease among low-income NHANES participants. J Nutr 140, 304-310.

9. Melgar-Quiñonez H, Ye Q, Zubieta AC et al. (2009) Assessing the monthly food abundance-shortage cycle in food insecure overweight women. J Nutr Educ Behav $\mathbf{4 1}$, s4.

10. Jones AD, Mundo-Rosas V, Cantoral A et al. (2017) Household food insecurity in Mexico is associated with the co-occurrence of overweight and anemia among women of reproductive age, but not female adolescents. Matern Child Nutr. Published online: 14 December 2016. doi: 10. 1111/mcn.12396.

11. Morales-Ruán MC, Méndez-Gómez Humarán I, ShamahLevy T et al. (2014) Food insecurity is associated with obesity in adult women of Mexico. Salud Pública Méx 56, S54-S61.

12. Kac G, Velásquez-Melendez G, Schlüssel MM et al. (2012) Severe food insecurity is associated with obesity among Brazilian adolescent females. Public Health Nutr 150, 1854-1860.

13. Himmelgreen DA, Romero-Daza N, Vega M et al. (2007) "The tourist season goes down but not the prices." Tourism and food insecurity in Rural Costa Rica. Ecol Food Nutr 45, 295-321.

14. Peterson K (2014) Household food insecurity and obesity risk in an urban slum in Brazil. MD Thesis, Yale University.

15. Vega-Macedo M, Shamah-Levy T, Peinador-Roldán R et al. (2014) Food insecurity and variety of food in Mexican households with children under 5 years. Salud Pública Méx 56, S21-S30.

16. Frongillo EA \& Bernal J (2014) Understanding the coexistence of food insecurity and obesity. Curr Pediatr Rev 2, 284-290.

17. Dhurandhar EJ (2016) The food-insecurity obesity paradox: a resource scarcity hypothesis. Physiol Behav 162 , 88-92.

18. Barrera-Cruz A, Rodríguez-González A \& Molina-Ayala MA (2013) Escenario actual de la obesidad en México (Current scenario of obesity in Mexico). Rev Med IMSS 51, 292-299.

19. Organisation for Economic Co-operation and Development (2017) Obesity Update 2017. Paris: OECD.

20. García-García E, De la Llata-Romero M, Kaufer-Horwitz M et al. (2008) La obesidad y el síndrome metabólico como problema de salud pública: una reflexión (Obesity and metabolic syndrome as a public health problem: a reflection). Salud Pública Méx 50, 530-547.

21. Shamah-Levy T, Ruiz-Matus C, Rivera-Dommarco J et al. (2017) Encuesta Nacional de Salud y Nutricion de Medio Camino 2016. Resultados Nacionales (Halfway National Health and Nutrition Survey 2016. National Results). Cuernavaca, Mexico: Instituto Nacional de Salud Pública.

22. Consejo Nacional de Evaluación de la Política de Desarrollo Social (CONEVAL) (2018) Medición de la Pobreza 2008-2018. Anexo Estadístico 2018 (Poverty Measurement 2008-2018. Statistical Annex 2018). https://www.coneval.org.mx/ Medicion/MP/Paginas/AE_pobreza_2018.aspx （accessed June 2020)

23. Mundo-Rosas V, Vizuet-Vega NI, Martínez-Domínguez J et al. (2018) Evolution of food insecurity in Mexican households: 2012-2016. Salud Pública Méx 60, 309-318.

24. Méndez-Gómez Humarán I, Pérez-Escamilla R, Shamah-Levy $\mathrm{T}$ et al. (2014) Household food insecurity, diabetes and hypertension among Mexican adults: results from Ensanut 2012. Salud Pública Méx 56, s62-s70.

25. Urquía-Fernández N (2014) La seguridad alimentaria en México (Food security in Mexico). Salud Pública Méx 56, s92-s98.

26. Morales-Ruán MC, Shamah-Levy T, Mundo-Rosas V et al. (2018) Evolución de los programas de ayuda alimentaria en México a través de información de la Ensanut MC 2016 (Evolution of the food aid programs in Mexico through information from ENSANUT MC 2016). Salud Pública Méx 60, 319-327.

27. Instituto Nacional de Salud Pública (2000) ENSANUT Encuesta Nacional de Salud y Nutrición (National Health and Nutrition Survey). https://ensanut.insp.mx/index.php (accessed June 2020).

28. Romero-Martínez M, Shamah-Levy T, Cuevas-Nasu L et al. (2017) Diseño metodológico de la Encuesta Nacional de Salud y Nutrición de Medio Camino 2016 (Methodological design of the Halfway National Health and Nutrition Survey 2016). Salud Pública Méx 59, 299-305.

29. Instituto Nacional de Estadística y Geografía (INEGI) (2019) Estadísticas a Propósito del día Internacional de las Personas de Edad ( $1^{\circ}$ De Octubre). Datos nacionales 2019 (Statistics on the International Elderlies Day (October 1st)). https://www. inegi.org.mx/contenidos/saladeprensa/aproposito/2019/ edad2019_Nal.pdf (accessed June 2020).

30. Villagómez-Ornelas P, Hernández-López P, CarrascoEnríquez B et al. (2014) Statistical validity of the Mexican food security scale and the Latin American and Caribbean food security scale. Salud Pública Méx 56, S5-S11.

31. Melgar-Quiñonez H, Alvarez Uribe MC, Fonseca Centeno ZY et al. (2010) Características psicométricas de la escala de seguridad alimentaria ELCSA aplicada en Colombia, Guatemala y México (Psychometric characteristics of the food security scale ELCSA applied in Colombia, Guatemala, and Mexico). Segurança Aliment Nutr 17, 48-60.

32. World Health Organization (2000) Obesity: Preventing and Managing the Global Epidemic: Report of a WHO Consultation. Report no. 894. Geneva: WHO.

33. Lohman TG, Roche AF \& Martorell R (1988) Anthropometric Standardization Reference Manual. Champaign, IL: Human Kinetics Books.

34. Habicht JP (1974) Estandarización de métodos epidemiológicos cuantitativos sobre el terreno (Standardization of quantitative epidemiological methods in the field). Bol Oficina Sanit Panam 76, 375-384.

35. Denova-Gutiérrez E, Ramírez-Silva I, Rodríguez-Ramírez S et al. (2016) Validity of a food frequency questionnaire to assess food intake in Mexican adolescent and adult population. Salud Pública Méx 58, 617-628.

36. Ramírez-Silva I, Jiménez-Aguilar A, Valenzuela-Bravo D et al. (2016) Methodology for estimating dietary data from the semi-quantitative food frequency questionnaire of the Mexican National Health and Nutrition Survey 2012. Salud Pública Méx 58, 629-638.

37. International Physical Activity Questionnaire Group (2010) Group Guidelines for Data Processing and Analysis of the International Physical Activity Questionnaire (IPAQ)-Short and Long Forms. https://sites.google.com/ site/theipaq/questionnaire_links (accessed June 2020).

38. Hirshkowitz M, Whiton K, Albert SM et al. (2015) National Sleep Foundation's sleep time duration recommendations: methodology and results summary. Sleep Health 1, 40-43.

39. Williams David K, Gauss CH, Bursac Z et al. (2018) Purposeful selection of variables in logistic regression. Source Code Biol Med. doi: 10.1186/1751-0473-3-17.

40. Janssen I, Katzmarzyk PT \& Ross R (2004) Waist circumference and not body mass index explains obesity-related health risk. Am J Clin Nutr 79, 379-384.

41. Shariff ZM \& Khor GL (2005) Obesity and household food insecurity: evidence from a sample of rural households in Malaysia. Eur J Clin Nutr 59, 1049-1058.

42. Mohammadi F, Omidvar N, Harrison GG et al. (2013) Is household food insecurity associated with overweight/ obesity in women? Iran J Public Health 42, 380-390.

43. Sawaya AL \& Roberts S (2003) Stunting and future risk of obesity: principal physiological mechanisms. Cad Saúde Pública 19, S21-S28. 
44. Gruenewald TL, Kemeny ME \& Aziz N (2006) Subjective social status moderates cortisol responses to social threat. Brain Behav Immun 20, 410-419.

45. Epel ES, McEwen B, Seeman T et al. (2000) Stress and body shape: stress-induced cortisol secretion is consistently greater among women with central fat. Psychosom Med 62, 623-632.

46. Laran J \& Salerno A (2013) Life-history strategy, food choice, and caloric consumption. Psychol Sci 24, 167-173.

47. Epel E, Lapidus R, McEwen B et al. (2001) Stress may add bite to appetite in women: a laboratory study of stress-induced cortisol and eating behavior. Psychoneuroendocrinology 26, 37-49.

48. Álvarez-Castaño LS, Goez-Rueda JD \& Carreño-Aguirre C (2012) Factores sociales y económicos asociados a la obesidad: los efectos de la inequidad y la pobreza (Social and economic factors associated with obesity: the effects of inequality and poverty). Rev Gerenc Polit Salud 11, 98-110.

49. Zaadstra BM, Seidell JC, Van Noord PAH et al. (1993) Fat and female fecundity: prospective study of effect of body fat distribution on conception rates. Obstet Gynecol Surv 48, 484-485.

50. Escobar C, González Guerra E, Velasco-Ramos M et al. (2013) Poor quality sleep is a contributing factor to obesity. Rev Mex Trastor Aliment 4, 133-142.

51. Guerrero-Zúñiga S, Gaona-Pineda EB, Cuevas-Nasu L et al. (2018) Prevalencia de síntomas de sueño y riesgo de apnea obstructiva del sueño en México (Prevalence of sleep symptoms and risk of obstructive sleep apnea in Mexico). Salud Pública Méx 60, 347-355.
52. Diario Oficial de la Federación (2014) Programa Nacional de Cultura Física y Deporte 2014-2018 (National Program of Physical Culture and Sports 2014-2018). Ciudad de México: DOF.

53. To QG, Frongillo EA, Gallegos D et al. (2014) Household food insecurity is associated with less physical activity among children and adults in the U.S. population. J Nutr 144, 1797-1802.

54. Perez Ferrer C, McMunn A, Rivera Dommarco JA et al. (2014) Educational inequalities in obesity among Mexican women: time-trends from 1988 to 2012. PLoS One 9, e97394.

55. Cohen AK, Rai M, Rehkopf DH et al. (2013) Educational attainment and obesity: a systematic review educational attainment and obesity. Obes Rev 14, 989-1005.

56. García-Obegón OP, Hernández LA, Ronquillo D et al. (2010) La Inseguridad Alimentaria de Mujeres en el Pasado se Asocia con Obesidad en el Presente (Women's food insecurity in the past is associated with obesity in the present). https://www.alanrevista.org/ediciones/2015/suplemento-2/ art-500/ (accessed June 2020).

57. Dietz WH (1994) Critical periods in childhood for the development of obesity. Am J Clin Nutr 59, 955-959.

58. Davies S (1993) Are coping strategies a cop out? IDS Bull 24, 60-72.

59. Leroy JL, Gadsden P, González de Cossío T et al. (2013) Cash and in-kind transfers lead to excess weight gain in a population of women with a high prevalence of overweight in rural Mexico. J Nutr 143, 378-383. 